\title{
Os desafios para uma nação conectada - indo além da introdução
}

\section{The challenges of connecting a nation - extending beyond the introduction}

\section{Los desafíos de conectarse una nación - yendo más allá de la introducción}

Veridiana Alimonti | veridiana.alimonti@gmail.com

Intervozes Coletivo Brasil de Comunicação Social. São Paulo, SP, Brasil

Resenha do livro: Pereira S, Biondi A, organizadores. Caminhos para a universalização da internet banda larga: experiências internacionais e desafios brasileiros. São Paulo: Intervozes; 2012.

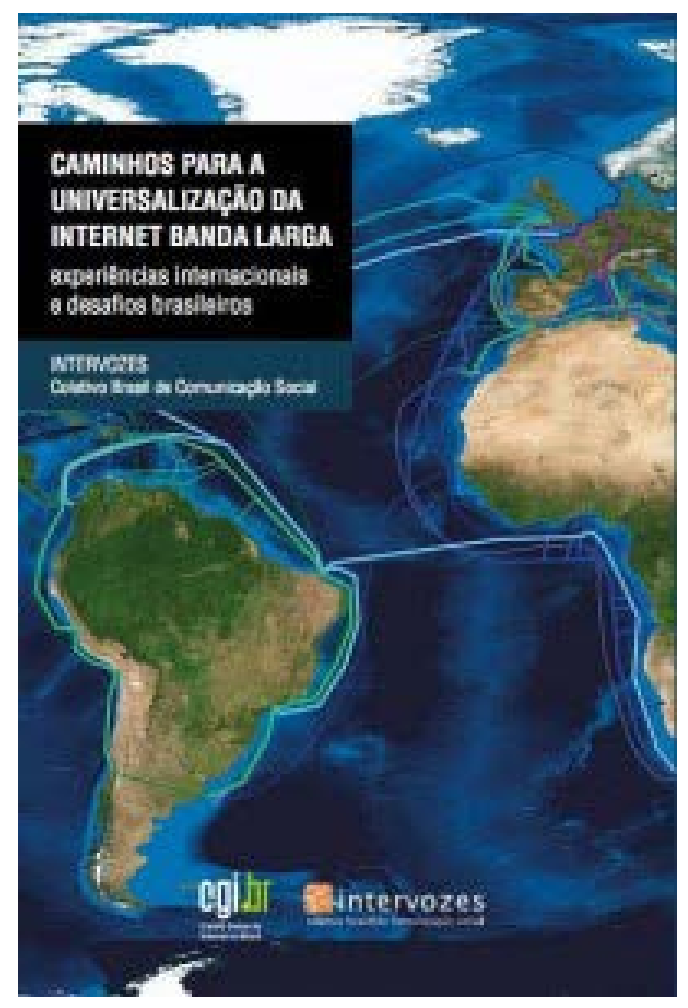

Palavras-chave: Acesso à internet; Conexão; Redes; Banda larga; Telecomunicações; Inclusão digital; Universalização; Marco Civil da Internet; Acesso aberto 
Do barulhinho da conexão discada até o acesso por diferentes dispositivos, onde e na hora que quiser, alguns anos se passaram, muitas decisões foram tomadas e importantes debates foram e continuam sendo travados. Se há os que podem gozar dos benefícios desse processo no país, ainda há muitos que seguem utilizando a conexão discada ou sequer possuem acesso à rede . O livro Caminhos para a universalização da internet banda larga: experiências internacionais e desafios brasileiros, realizado pelo Coletivo Intervozes, com apoio do Comitê Gestor da Internet no Brasilii, traz um panorama completo e interessante das questões que envolvem a garantia do acesso à internet e da troca de informações e conteúdos pela rede.

Começando do mais básico sobre a internet banda larga, suas características, elementos de rede e tipos de tecnologias, o livro se aprofunda expondo complexas discussões sobre a regulação de serviços e de infraestrutura, o papel do Estado na condução de políticas públicas, os direitos autorais na dinâmica de criação e compartilhamento proporcionada pelas redes, entre outros, apontando a trilha das disputas presentes nos variados temas. A obra se divide em três partes, apresentando experiências e dados de outros países, analisando a situação brasileira em perspectiva comparada e oferecendo um conjunto de entrevistas com acadêmicos, ativistas digitais, entidades de defesa do consumidor, empresários e representantes de governo.

Quanto à trilha das disputas, o próprio título já destaca uma das principais, ao menos no Brasil, explicitando a sua posição no debate. Trata-se da defesa da universalização do acesso à internet, em que a perspectiva da garantia de direitos se sobrepõe à lógica de mercado.

\section{Universalização e essencialidade}

O reconhecimento de que um determinado serviço é essencial às pessoas pela importância que assume, no dia a dia, para o exercício e a concretização de direitos tem reflexos diretos na maneira como ele é regulado pelo Estado e explorado pelos agentes privados. No âmbito dos serviços de telecomunicações, a telefonia fixa contou com esse status durante a maior parte do século XX, mas já há alguns anos perde espaço significativo para a telefonia móvel e, em especial, para a banda larga (fixa ou móvel).

Estar conectado à rede potencializa o acesso à informação, o exercício do direito à educação e à cultura, a possibilidade de se expressar e interagir com um contingente enorme de pessoas, além de permitir a reinvenção da relação do poder público com os cidadãos por meio das aplicações de governo eletrônico, da ampliação da transparência e do estímulo à participação social na elaboração de normas e na implementação de políticas públicas. As redes são também mecanismos de pressão e de mobilização, frente aos governos e aos agentes privados. Elas não deixam de servir igualmente a objetivos mais triviais, consolidando-se como parte da rotina de quem pode acessá-las - em transações bancárias, na declaração de imposto de renda, na comunicação interpessoal, na comercialização de produtos e serviços etc.

Neste sentido, o livro destaca que diferentes países passaram a reconhecer o acesso à internet como um direito ao longo do século XXI. Primeiro, Estônia, depois, França, Grécia, Espanha e Finlândia. O mesmo ocorreu no Brasil, mas somente em 2014, com a aprovação do Marco Civil da Internet (Lei No 12.965/2014). Em seu art. $4^{\circ}$, inciso I, a lei estabelece que "a disciplina do uso da internet no Brasil tem por objetivo a promoção do direito de acesso à internet a todos". Já seu art. $7^{\circ}$ afirma que "o acesso à internet é essencial ao exercício da cidadania [...]".

Apesar do reconhecimento legal, a regulação do serviço de telecomunicações que dá suporte ao acesso à internet segue como se isso não tivesse ocorrido. Cumpre registrar que, para esse acesso, são necessários

\footnotetext{
i De acordo com a pesquisa TIC Domicílios, realizada entre o final de 2013 e início de 2014, 56\% dos domicílios brasileiros estão desconectados, sendo que $10 \%$ das moradias conectadas possuem acesso discado à internet. As proporções são piores se consideramos as classes mais baixas ou a área rural. [citado 22 fev 2015] Disponível em: http://cetic.br/pesquisa/domicilios/ indicadores.

ii A íntegra do livro e outros conteúdos relacionados podem ser acessados em: http://www.caminhosdabandalarga.org.br/. O livro conta com diferentes colaboradores, tendo sido organizado pelos pesquisadores Sivaldo Pereira da Silva e Antonio Biondi.
} 
tanto a infraestrutura de telecomunicações e o serviço de telecomunicações quanto o serviço de conexão à internet, que se utiliza dos primeiros, mas não se confunde com eles ${ }^{\text {iii. }}$. No que toca às telecomunicações, a Lei Geral de Telecomunicações - LGT (Lei No 9.472/1997) classifica a prestação desses serviços em dois regimes distintos: o regime público e o regime privado.

No primeiro caso, há obrigação de universalização, isto é, o serviço deve estar disponível a qualquer pessoa independentemente da sua localização ou condição socioeconômica, razão pela qual o poder público tem a prerrogativa de estabelecer metas de universalização aos prestadores privados. Porém, não basta que o serviço esteja disponível se a sua tarifa for impeditiva ao acesso da população em geral. Por isso, o serviço está sujeito à modicidade tarifária e o poder público tem competência para fixar os seus valores. No segundo caso, os preços são livres e a não ser que a sua prestação envolva a exploração de radiofrequência, como no serviço móvel, é bastante reduzida a capacidade do governo de determinar às operadoras que invistam onde não lhes interessa.

Não à toa, o art. $65, \S^{\circ}$ da LGT estabelece que "Não serão deixadas à exploração apenas em regime privado as modalidades de serviço que, sendo essenciais, estejam sujeitas a deveres de universalização.” Todavia, no Brasil, os serviços de telecomunicações ligados à banda larga são prestados exclusivamente em regime privado, apesar da pressão já realizada há alguns anos por organizações da sociedade civil para que parte dessa exploração ocorra em regime público ${ }^{\text {iv }}$.

O Programa Nacional de Banda Larga (PNBL), lançado em 2010, reflete essa opção do governo nos seus fracos resultados. Uma das medidas mais interessantes e ousadas do PNBL - a reativação da Telebras para a gestão e implementação de uma rede nacional de fibra óptica - ficou bem aquém das expectativas, por dificuldades burocráticas, políticas e econômicas. O livro aborda a problemática do PNBL, bem como traz parâmetros de outros planos nacionais em termos de metas previstas e do papel assumido pelo Estado e por agentes privados, preocupando-se em tratar de países centrais e periféricos.

Além dos planos nacionais, o estudo apresenta como diferentes países enfrentaram outros aspectos do desafio de democratizar o acesso à banda larga, serviço que exige altos investimentos iniciais, tendendo à formação de monopólios ou oligopólios e à perpetuação das disparidades econômicas e sociais. As iniciativas contempladas pelos autores não estão centradas apenas nas políticas de âmbito federal; eles atentam também para as experiências de redes públicas de acesso à internet sem fio em cidades como Barcelona (Espanha), Taipei (Taiwan) e Helsinque (Finlândia).

\section{Os desafios não se restringem ao acesso}

Porém, quando o assunto é internet, o acesso é só o começo. Como o livro destaca, a própria noção de inclusão digital não se encerra no provimento da conexão à rede. É preciso que as pessoas saibam usar seus recursos e, mais do que isso, apropriem-se da tecnologia para não serem apenas usuárias, mas criadoras, de conteúdos, programas e aplicações. Tal preocupação se torna ainda mais premente ao considerarmos os portadores de necessidades especiais, que nas tecnologias da informação e da comunicação podem

iii O serviço de conexão à internet é considerado um serviço de valor adicionado, cuja definição legal prevista na Lei Geral de Telecomunicações é: "a atividade que acrescenta, a um serviço de telecomunicações que the dá suporte e com o qual não se confunde, novas utilidades relacionadas ao acesso, armazenamento, apresentação, movimentação ou recuperação de informações". A lei complementa ainda: "Serviço de valor adicionado não constitui serviço de telecomunicações, classificando-se seu provedor como usuário do serviço de telecomunicações que lhe dá suporte, com os direitos e deveres inerentes a essa condição". Ver também Norma 04/1995, do Ministério das Comunicações. Agência Nacional de Telecomunicações. Norma 004/95: uso de meios da rede pública de telecomunicações para acesso à internet. [local desconhecido]: Agência Nacional de Telecomunicações (BR); 1995 [citado 1 fev. 2015]. Disponível em: http://www.anatel.gov.br/Portal/verificaDocumentos/documento.asp? numeroPublicacao=10 283\&assuntoPublicacao=Norma\%20MC\%20n\%BA\%20004/1995\&caminhoRel=null\&filtro=1\&documentoPath=biblioteca/Normas/ Normas MC/norma 004 95.html

iv Em 2013, a Campanha Banda Larga é um direito seu, integrada pelo Coletivo Intervozes, apresentou ao Ministério das Comunicações e à Anatel uma proposta para a universalização do acesso à internet no país mas, até o momento, não houve alterações na política conduzida pelo governo federal. A proposta pode ser acessada em: http://www.campanhabandalarga.com.br/ proposta/. [citado $11 \mathrm{fev} 2015$ ] 
encontrar uma aliada ou um novo empecilho no seu dia a dia. Apontando para o primeiro caminho, já há padrões consistentes formulados internacionalmente para uma navegação mais acessível na web.

Outra ordem de dificuldades pode existir, ainda, a depender dos grupos sociais, étnicos ou comunidades linguísticas que se tenha em consideração. Retomando citação presente no livro, "incluir digitalmente significa estimular e viabilizar condições materiais e não-materiais para que cada grupo social possa produzir sua própria visão da realidade, interpretando, criando e difundindo informações capazes de qualificar sua intervenção no mundo e instrumentalizar, no plano maior, a defesa de seus direitos"v.

Para que esse processo mais amplo possa se efetivar, devemos atentar a outros pontos centrais, que suscitam grandes disputas e controvérsias. O primeiro deles é a neutralidade da rede, mencionado no estudo como um dos debates fundamentais travados atualmente. Esse princípio afirma o tratamento isonômico dos pacotes de dados que trafegam na internet, sem distinção por origem ou destino, conteúdo, serviço, terminal ou aplicação.

Tal garantia visa impedir o bloqueio, a degradação e o privilégio de conteúdos por razões políticas, morais ou comerciais. Destina-se também a combater modelos de negócios baseados na segmentação da internet, que retira dos planos mais baratos o acesso às aplicações que geram mais tráfego ou que, por força de parcerias comerciais, incentiva a navegação em plataformas e sites específicos, por exemplo, deixando de descontar esse acesso da franquia de dados contratada pelo usuário. No Brasil, a neutralidade da rede está prevista no art. $9^{\circ}$ do Marco Civil da Internet, que permite algumas possibilidades técnicas de discriminação ou degradação do tráfego de pacote de dados, a serem regulamentadas por decreto.

Outro ponto central é a batalha que contrapõe, de um lado, restrições à cópia, compartilhamento e remixagem de conteúdos e, de outro, o acesso ao conhecimento, a liberdade de expressão e a efervescência da cultura digital. A polêmica em torno dos direitos autorais muitas vezes não diz realmente respeito à proteção dos interesses dos autores, mas dos antigos e novos intermediários da cadeia de "consumo" cultural (a indústria fonográfica, cinematográfica, editorial ou as novas plataformas online que servem à difusão de conteúdos).

A potencialização da circulação da informação, do conhecimento e da cultura com a internet colocou em xeque modelos de produção e distribuição de bens culturais e informacionais, permitindo o surgimento de modelos alternativos, calcados ou não na perspectiva do acesso ao conhecimento. As reações negativas e restritivas a esse movimento envolvem criminalização, remoção de conteúdo, corte da conexão e pagamento de altos valores. O livro traz um capítulo específico sobre o assunto, apresentando o histórico do debate e as experiências em diferentes países, como Estados Unidos, França, Colômbia e Brasil.

Por fim, há o ponto da privacidade e dos dados pessoais. Embora não seja abordado em muitos detalhes na obra, trata-se de tema cada vez mais candente, considerando que a internet e as novas tecnologias da informação e da comunicação aceleraram e aprofundaram a coleta e o tratamento de dados pessoais. Seja pelo intuito vigilante, por parte dos Estados, de obter informações de usuários da rede de forma massiva e arbitrária, seja pelas motivações comerciais dos mais variados sites e plataformas online de conhecerem tudo sobre o usuário para monetizarem esses dados, a situação atual já é extremamente preocupante.

O acesso à internet, que é essencial ao exercício da cidadania e direito de todos, só se justifica e cumpre efetivamente seu papel se for estruturado e universalizado com base no respeito e na promoção de direitos humanos fundamentais, como a liberdade de expressão, o acesso à informação e a privacidade.

v Ferraz J, Lemos R. Pontos de Cultura e Lan House: estruturas para inovação na base da pirâmide social. Rio de Janeiro: Centro de Tecnologia e Sociedade da Fundação Getúlio Vargas; 2011. In: Peareira S, Biondi A, organizadores. Caminhos para a universalização da banda larga: experiências internacionais e desafios brasileiros. São Paulo: Intervozes; 2012. p. 200-201. 


\section{Para onde e como ir?}

Em seu último capítulo, o livro sintetiza cinco nós considerados fundamentais para se alcançar a universalização da banda larga, compreendendo a tarefa na perspectiva ampla já assinalada aqui. Ele parte dos problemas verificados na realidade brasileira e dos aspectos positivos das experiências internacionais para traçar caminhos voltados para (i) o fortalecimento da ação do Estado; (ii) melhorias nos sistemas de transparência, accountability e gestão das políticas públicas e da regulação; (iii) a criação de um ambiente de competitividade e concorrência de mercado; (iv) o desenvolvimento de infraestrutura para o tráfego de dados; e (v) a ênfase na apropriação social do acesso à internet como um direito do cidadão.

Ainda que o estudo tenha sido editado em 2012, os desafios, críticas e disputas apresentados por ele permanecem na ordem do dia e com contornos bastante semelhantes. A universalização do acesso à banda larga foi tema de destaque na campanha de Dilma Rousseff para o seu segundo mandato, alterando ao menos o discurso do governo que, desde seu início, fazia referência apenas à "massificação" do serviço, de modo a afastar os condicionamentos da LGT ligados ao regime público. A adoção do novo termo, porém, não refletiu até o momento na decisão de alterar o regime de prestação do serviço de comunicação de dados.

De maneira geral, ainda não está claro o seguimento das políticas para banda larga na gestão iniciada recentemente. Se, por um lado, isso pode indicar planos não amadurecidos, por outro, pode ser a oportunidade para debater e pressionar por ações e políticas mais alinhadas ao interesse público, desde que se garanta a participação social tão deficiente nesse campo no primeiro mandato.

Em complemento, está em curso o processo de regulamentação do Marco Civil da Internet, que deverá ocorrer por decreto presidencial e repete a experiência exitosa de construção participativa do projeto de lei, ao abrir debate público na internet para que os cidadãos enviem suas contribuições ${ }^{\text {vi. }}$ Entre os assuntos espinhosos a serem enfrentados estão as exceções técnicas à discriminação de pacotes de dados na internet, definição ligada à proteção da neutralidade da rede, e o detalhamento das obrigações de guarda de registros de conexão e de acesso a aplicações online para investigações de ilícitos na internet.

Ainda no tema da privacidade e da proteção de dados pessoais, o início de 2015 marcou a retomada do Anteprojeto de Lei de Proteção de Dados Pessoais, que passou por consulta pública no final de 2010 e permaneceu em discussão interna no governo por quatro anos. Também neste caso foi aberto debate público vii para que a sociedade opine sobre como deve ser o regime geral de proteção de dados pessoais no Brasil, legislação que diferentes países já possuem há anos e que é fundamental para estabelecer princípios, procedimentos e suporte institucional ao direito do cidadão de ter o controle sobre seus próprios dados.

As intrincadas e tensas disputas em torno dos rumos da rede, tanto no que diz respeito ao acesso quanto às questões que se colocam após a conexão, têm impacto generalizado no dia a dia da população. A própria falta de acesso à internet é um desses impactos. Democratizar a compreensão dessas discussões de forma a envolver um público mais amplo na definição de seus desdobramentos é passo crucial para o desafio de democratizar o acesso à rede e para a apropriação social das tecnologias da informação e da comunicação. O livro Caminhos para a universalização da internet banda larga é uma bela contribuição neste sentido.

vi As contribuições podem ser enviadas até 31 de março de 2015 por aqui: http://participacao.mj.gov.br/marcocivil/. É possível que haja uma segunda fase de debate a partir de texto mais consolidado.

vii As contribuições podem ser enviadas até 30 de abril de 2015 por aqui: http://participacao.mj.gov.br/dadospessoais/ 